DOI: 10.20472/IAC.2019.050.028

\author{
SIRISUHK RAKTHIN \\ College of Management, Mahidol University, Thailand \\ NATTAWAT PISITSUPAKARN \\ College of Management, Mahidol University, Thailand \\ KARUNA AKSARAVUT \\ College of Management, Mahidol University, Thailand
}

\title{
FACTORS INFLUENCING EMPLOYEE ENGAGEMENT IN THAI SMES
}

\begin{abstract}
:
Successful organization, in any size or type, must have engaged employees who have high potential, positive attitude, and devotion to do their job well. Employee engagement became more vital to small and medium-sized enterprises (SMEs) since they posses much fewer resources than large organizations. In Thailand, there are currently 2.9 million SMEs, which account for $99.6 \%$ of all business entities and employ 10.5 million people, or $77.8 \%$ of total Thai workforce. Although SMEs play a critical role in Thai Economy, most Thai SMEs still face many challenges - limited competency and accessibility to sources of funds, IT competency, government business promotions services, and global markets. Limited resource accessibility for SMEs results in high employee turnover rate. Consequently, it is vital that Thai SMEs should adopt meaningful HR management tools to improve their long-term business sustainability.

This research study aims to explore how employee's 1) self-leadership, 2) interpersonal leadership, 3) process leadership, 4) adaptability, and 5) remuneration satisfaction could influence employee engagement in Thai SMEs. Also, the mediating effects of job satisfaction in these relationships are examined. Data have been collected via questionnaires from 497 employees in Thai SMES and hypotheses were tested using the partial least squares structural equation modeling (PLS-SEM). The results indicate that employee's 1 ) self-leadership, 2) interpersonal leadership, 3) adaptability, and 4) satisfaction on existing remuneration have positive impacts on employee engagement. In addition, our results demonstrate that job satisfaction partially mediates relationships between 1 ) interpersonal leadership and 2) remuneration satisfaction and the SMEs' employee engagement. The research study demonstrates the value of employees' leadership, adaptability and satisfaction in increasing employee engagement, particularly in SMEs context. The research result can pave a path for better HR management in Thai SMEs, e.g., leadership training, compensation package design, and etc.
\end{abstract}

\section{Keywords:}

Leadership, Employee Engagement, Job Satisfaction, SMEs, Thailand

JEL Classification: J28, C30, M10 